\title{
Erratum to: Alzheimer's disease, but not ageing or depression, affects dual-tasking
}

\author{
Reiner Kaschel · Robert H. Logie • Miguel Kazén • \\ Sergio Della Sala
}

Published online: 13 November 2009

(C) Springer-Verlag 2009

Erratum to: J Neurol (2009) 256:1860-1868

DOI 10.1007/s00415-009-5210-7

The article was published without acknowledgement.

The Acknowledgement is given here.

\section{Acknowledgements}

This work has been funded by the grant AS-90-2007 awarded by the Alzheimer's Society to Sergio Della Sala and Robert H. Logie.

The online version of the original article can be found under doi:10.1007/s00415-009-5210-7.

R. Kaschel · M. Kazén

Institute of Psychology, Department of Human Sciences,

University of Osnabrück, Seminarstr. 20,

49074 Osnabrück, Germany

e-mail: reiner.kaschel@web.de

M. Kazén

e-mail: mikazen@uos.de

R. H. Logie · S. Della Sala ( $\square)$

Department of Psychology, Centre for Cognitive Ageing and

Cognitive Epidemiology, Human Cognitive Neuroscience,

University of Edinburgh, Edinburgh EH8 9JZ, UK

e-mail: sergio@ed.ac.uk

R. H. Logie

e-mail: rlogie@staffmail.ed.ac.uk 